Open Access

\title{
Permanent draft genome sequence of sulfoquinovose-degrading Pseudomonas putida strain SQ1
}

\author{
Ann-Katrin Felux ${ }^{1,2}$, Paolo Franchini $i^{1,3}$ and David Schleheck ${ }^{1,2^{*}}$
}

\begin{abstract}
Pseudomonas putida SQ1 was isolated for its ability to utilize the plant sugar sulfoquinovose (6-deoxy-6-sulfoglucose) for growth, in order to define its SQ-degradation pathway and the enzymes and genes involved. Here we describe the features of the organism, together with its draft genome sequence and annotation. The draft genome comprises $5,328,888$ bp and is predicted to encode 5,824 protein-coding genes; the overall $\mathrm{G}+\mathrm{C}$ content is $61.58 \%$. The genome annotation is being used for identification of proteins that might be involved in SQ degradation by peptide fingerprinting-mass spectrometry.
\end{abstract}

Keywords: Pseudomonas putida SQ1, aerobic, Gram-negative, Pseudomonadaceae, plant sulfolipid, organosulfonate, sulfoquinovose biodegradation

\section{Introduction}

Pseudomonas putida strain SQ1 belongs to the family of Pseudomonadaceae in the class of Gammaproteobacteria. The genus Pseudomonas was first described by Migula (in the year 1894 [1]) and the species Pseudomonas putida by Trevisan (in 1889 [2]). P. putida strain KT2440 was the first strain whose genome had been sequenced (in 2002 [3]), and it is the most well-studied $P$. putida strain thus far [4]. Currently, there are more than 30 genome sequences of $P$. putida strains available (e.g., 12 complete and 24 draft genomes in NCBI; January 2015), including the complete genome sequence of type strain NBRC $14164^{\mathrm{T}}$ [5]. P. putida species are highly abundant in water, soil and in the rhizosphere [6,7], can be plant-beneficial [8], and are extensively studied for their capabilities to degrade a broad range of substrates, especially aromatic compounds [9-12].

P. putida strain SQ1 was isolated for its ability to utilize the sulfonated plant sugar sulfoquinovose (6-deoxy6-sulfoglucose) as a sole source of carbon and energy for growth, and was enriched from a sample of littoral

\footnotetext{
* Correspondence: david.schleheck@uni-konstanz.de

${ }^{1}$ Department of Biology, University of Konstanz, Konstanz, Germany ${ }^{2}$ Konstanz Research School Chemical Biology, University of Konstanz, Konstanz, Germany

Full list of author information is available at the end of the article
}

sediment of pre-Alpine Lake Constance, Germany [13]. SQ is the polar headgroup of the plant sulfolipid sulfoquinovosyl diacylglycerol, which is present in the photosynthetic membranes of all higher plants, mosses, ferns and algae and most photosynthetic bacteria [14]. $\mathrm{SQ}$ is one of the most abundant organosulfur compounds in the biosphere, following glutathione, cysteine, and methionine, and the global production of SQ is estimated at 10 gigatons $\left(10^{10}\right.$ tons) per year [15]. Hence, the complete degradation of SQ concomitant with a recycling of the bound sulfur in form of inorganic sulfate is an important process of the carbon and sulfur cycle, e.g. in soils.

Until today only one bacterial degradation pathway for SQ has been identified, 'sulfoglycolysis' in Escherichia coli $\mathrm{K}-12$ [16]. In this pathway, SQ is catabolized in analogy to glucose-6-phosphate via an adapted EmbdenMeyerhof-Parnas (glycolysis) pathway, involving four newly identified enzymes and genes, and four newly identified metabolites. The pathway yields dihydroxyacetone phosphate (DHAP), which drives energy metabolism and growth of $E$. coli, and sulfolactaldehyde, which is reduced to dihydroxypropanesulfonate and excreted [16]. For Pseudomonas species, it is well-known that these bacteria lack the key enzyme for glycolysis, 
phosphofructokinase, but that the alternative EntnerDoudoroff pathway is operative, i.e., an oxidative entry into glucose-6-phosphate catabolism via a dehydrogenase enzyme. We detected a SQ-dehydrogenase activity in crude extract of SQ-grown P. putida SQ1 cells, and we therefore suspect that a 'Sulfo-Entner-Doudoroff'-type of pathway might be operative in P. putida SQ1 for catabolism of SQ, but not sulfoglycolysis.

A draft genome sequence of strain SQ1 has been established and annotated in the IMG pipeline, and the annotation has been transferred to a proteomics (Mascot) database for peptide fingerprinting-mass spectrometry: in our present (unpublished) work, the database is used to identify enzymes and genes that are specifically induced during growth with $\mathrm{SQ}$, e.g. in comparison to cells grown with glucose, by two-dimensional protein gel electrophoresis. Here, we present a summary classification and a set of features for Pseudomonas putida strain SQ1, together with the description of the shotgun genomic sequencing and annotation.

\section{Organism Information}

\section{Classification and features}

P. putida SQ1 is a rod-shaped (Fig. 1), motile, Gramnegative bacterium that grows aerobically in complex medium (e.g. LB-medium), or prototrophically in mineralsalts medium with a single carbon source (e.g., succinate, glucose, SQ). Strain SQ1 grows overnight on LB-agar plates and forms beige-whitish, smooth colonies (Table 1). Pseudomonas putida SQ1 has been deposited in the Leibniz Institute DSMZ-German Collection of Microorganisms and Cell Cultures under reference number DSM 100120.
Based on its 16S rRNA gene sequence, strain SQ1 is a member of the genus and species Pseudomonas putida, which is placed in the family Pseudomonadaceae within the order Pseudomonadales of Gammaproteobacteria, as illustrated by a phylogenetic tree shown in Fig. 2. Currently, 1,732 genome sequences of member of the order Pseudomonadales of Gammaproteobacteria, and 707 genome sequences within the family Pseudomonadaceae have been established (IMG JGI, January 2015).

\section{Genome sequencing information}

\section{Genome project history}

The DNA sample was submitted to GATC Biotech (Konstanz, Germany) in December 2012 where the whole-genome shotgun sequencing phase was completed in April 2013; the whole-genome shotgun sequencing was performed by GATC using the Illumina HiSeq2000 platform and a 100-bp paired-end library. After the mapping and de-novo assembly of the unmapped reads, which was done at the Genomics Center of the University of Konstanz, the draft genome sequence was uploaded into the IMG Pipeline for annotation and presented for public access on December 2014. The draft genome annotation is available at IMG under the IMG submission ID 14279, and was also deposited in Genbank under the accession number JTCJ00000000. Table 2 presents the project information and its association with MIGS version 2.0 compliance [17].

\section{Growth conditions and genomic DNA preparation}

Genomic DNA was extracted from an overnight culture of $P$. putida SQ1 grown at $30{ }^{\circ} \mathrm{C}$ in LB medium (500-ml

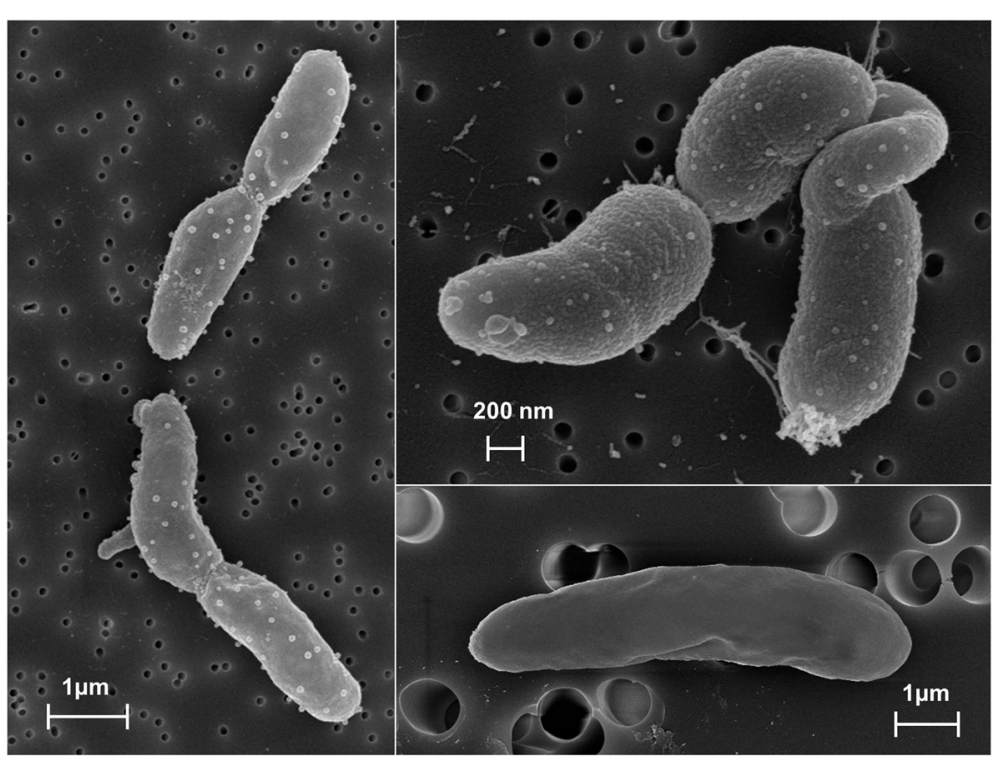

Fig. 1 Scanning electron micrographs of Pseudomonas putida SQ1. Cells derived from a liquid culture (LB medium) 
Table 1 Classification and general features of Pseudomonas putida SQ1 [32]

\begin{tabular}{|c|c|c|c|}
\hline MIGS ID & Property & Term & Evidence code $\mathrm{a}^{\mathrm{a}}$ \\
\hline & Current & Domain Bacteria & TAS [33] \\
\hline & & Phylum Proteobacteria & TAS [34] \\
\hline & & Class Gammaproteobacteria & TAS $[34,35]$ \\
\hline & & Order Pseudomonadales & $\operatorname{TAS}[36,37]$ \\
\hline & & Family Pseudomonadaceae & TAS $[38,39]$ \\
\hline & & Genus Pseudomonas & TAS $[1,38-40]$ \\
\hline & & Species putida & TAS $[1,2]$ \\
\hline & & Strain SQ1 & TAS [13] \\
\hline & Gram stain & Negative & TAS [13] \\
\hline & Cell shape & Rod-shaped & TAS [13] \\
\hline & Motility & Motile & TAS [13] \\
\hline & Sporulation & Non-sporulating & TAS [13] \\
\hline & $\begin{array}{l}\text { Temperature } \\
\text { range }\end{array}$ & Mesophile & TAS [13] \\
\hline & $\begin{array}{l}\text { Optimum } \\
\text { temperature }\end{array}$ & $30{ }^{\circ} \mathrm{C}$ & TAS [13] \\
\hline & $\begin{array}{l}\text { pH range; } \\
\text { Optimum }\end{array}$ & Not tested; 7.2 & TAS [13] \\
\hline & $\begin{array}{l}\text { Carbon } \\
\text { source }\end{array}$ & $\begin{array}{l}\text { Succinate, glucose, } \\
\text { sulfoquinovose }\end{array}$ & IDA,TAS [13] \\
\hline & $\begin{array}{l}\text { Energy } \\
\text { source }\end{array}$ & Chemoorganotroph & IDA,TAS [13] \\
\hline MIGS-6 & Habitat & Aerobic habitat & TAS [13] \\
\hline MIGS-22 & $\begin{array}{l}\text { Oxygen } \\
\text { requirement }\end{array}$ & Aerobic & TAS [13] \\
\hline MIGS-15 & $\begin{array}{l}\text { Biotic } \\
\text { relationship }\end{array}$ & Free-living & NAS \\
\hline MIGS-14 & Pathogenicity & $\begin{array}{l}\text { Potentially pathogenic, Risk } \\
\text { group } 2 \text { (classification } \\
\text { according to German TRBA) }\end{array}$ & \\
\hline MIGS-4 & $\begin{array}{l}\text { Geographic } \\
\text { location }\end{array}$ & $\begin{array}{l}\text { Isolated from littoral } \\
\text { sediment of Lake Constance, } \\
\text { Germany }\end{array}$ & TAS [13] \\
\hline MIGS-5 & $\begin{array}{l}\text { Collection } \\
\text { date }\end{array}$ & 2011 & TAS [13] \\
\hline \multirow{2}{*}{$\begin{array}{l}\text { MIGS-4.1 } \\
\text { MIGS-4.2 }\end{array}$} & Latitude & $47^{\circ} 41^{\prime} 44.77^{\prime \prime} \mathrm{N}$ & \\
\hline & Longitude & $9^{\circ} 11^{\prime} 34.76 " E$ & \\
\hline MIGS-4.4 & Altitude & $399 m$ & \\
\hline
\end{tabular}

aEvidence codes - IDA: Inferred from Direct Assay; TAS: Traceable Author Statement (i.e., a direct report exists in the literature); NAS: Non-traceable Author Statement (i.e., not directly observed for the living, isolated sample, but based on a generally accepted property for the species, or anecdotal evidence). These evidence codes are from the Gene Ontology project [32]

scale), using JGI`s Bacterial Genomic DNA isolation protocol (CTAB protocol 2012).

\section{Genome sequencing and assembly}

The whole-genome shotgun sequencing was performed under contract by GATC Biotech (Konstanz, Germany)

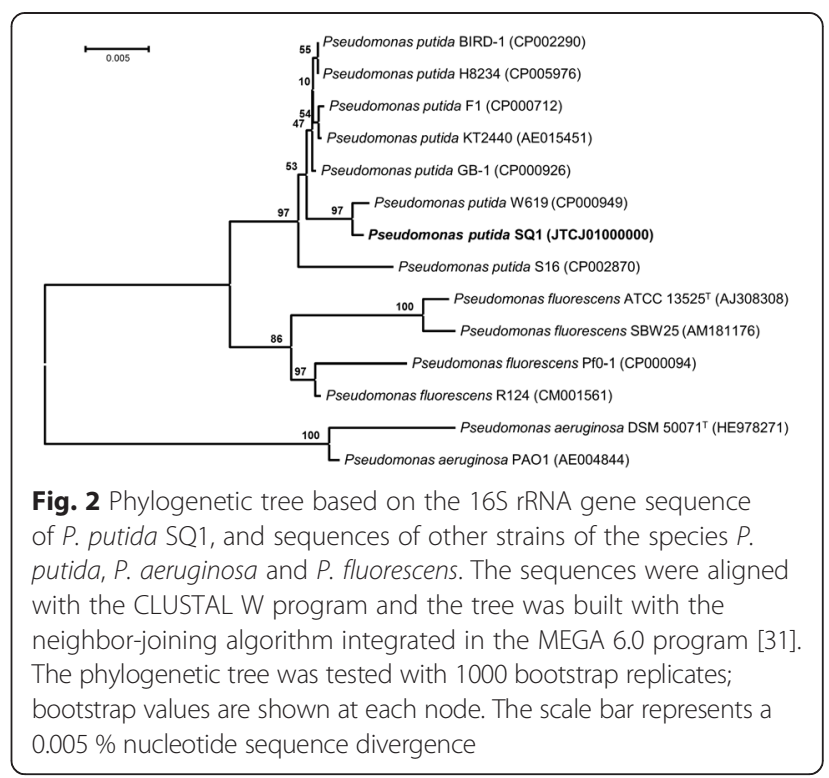

using the Illumina HiSeq2000 platform and a 100-bp paired-end library, which resulted in 23,816,201 sequenced reads $\left(1.85 \times 10^{9}\right.$ total bases $)$. The trimming, mapping, as well as the de novo assembly of the unmapped raw reads, was performed at the Genomics Center of the University of Konstanz, Germany. First, the remaining adapters were removed and reads were trimmed by quality in CLC Genomics Workbench v6.5 (CLC bio, Aarhus, Denmark). In the next step, Bowtie v2.2.3 [18] was used to align the filtered reads against the genome of the closest relative, $P$. putida strain W619, to which 21,943,994 reads matched. These mapped reads were assembled with a reference-guided approach using the Columbus module implemented in Velvet v1.2.10 [19]. Velvet was then used to de novo assemble also all unmatched 1,872,207 reads ( $8.5 \%$ of total reads). The whole process resulted in a total number of 1,634 contigs larger than $200 \mathrm{bp}$; the largest contig is $37,533 \mathrm{bp}$. The size of the draft genome is $5.3 \mathrm{Mb}$ with 4,750,611 DNA coding bases, which is a normal size compared to other known P. putida genomes (range 3.0 to $7.1 \mathrm{Mb}$ ). The average $\mathrm{G}+\mathrm{C}$ content is $61.58 \%$. At this time, no additional work is planned for this genome sequencing project (labeled as Permanent Draft).

\section{Genome annotation}

Genes were identified and auto-annotated in the DOEIMG pipeline [20]. Genes were identified using Prodigal [21] and the predicted CDGs were translated and used to search the National Center for Biotechnology Information (NCBI) nonredundant database, UniProt [22], TIGRFam [23], Pfam [24], KEGG [25], COG [26], and InterPro [27] databases. The tRNAscan-SE tool [28] was used to identify tRNA sequences, whereas ribosomal 
Table 2 Project information

\begin{tabular}{lll}
\hline MIGS ID & Property & Term \\
\hline MIGS-31 & Finishing quality & Permanent draft \\
MIGS-28 & Libraries used & 100-bp paired-end library \\
MIGS-29 & Sequencing platforms & Illumina HiSeq2000 \\
MIGS-31.2 & Fold coverage & $>10 x$ \\
MIGS-30 & Assemblers & Velvet v1.2.10 \\
MIGS-32 & Gene calling method & Prodigal \\
& Genbank ID & JTCJ00000000 \\
& Genbank Date of Release & December 16, 2014 \\
& GOLD ID & Gi0045313 \\
& BIOPROJECT & PRJNA266268 \\
MIGS 13 & Source Material Identifier & DSM 100120 \\
& Project relevance & Study of unknown \\
& & degradation pathway \\
\hline
\end{tabular}

RNA sequences were identified by searches against models of the ribosomal RNA genes built from SILVA [29]. The RNA components of the protein secretion complex and the RNaseP were identified by searching the genome of the corresponding Rfam profiles using INFERNAL.

\section{Genome properties}

The draft genome assembly of $P$. putida SQ1 consists of 1,634 contigs with an overall $\mathrm{G}+\mathrm{C}$ content of $61.58 \%$. For these contigs, 5,925 complete genes or partial genes at ends of contigs have been predicted, 5,824 (98.30\%) of which for protein-coding genes. 4,624 (78.04\%) of these were assigned to a putative function with the remaining annotated as hypothetical proteins. The draft genome annotation predicted also 101 (1.70 \%) sequences of RNA coding genes. The properties and the statistics of the draft genome annotation are summarized in Table 3 and the distribution of genes into COGs functional categories is presented in Table 4.

Currently, there are 50 genome sequencing projects for Pseudomonas putida strains registered in the JGI Genomes Online Database (GOLD), and 32 P. putida genome sequences (finished or permanent draft) are accessible within the IMG database (January 2015) for direct comparison; their genome sizes range between 3.0 Mb (P. putida MR3) and 7.1 Mb (P. putida S12), and their overall $\mathrm{G}+\mathrm{C}$ content ranges between $60.81 \%$ (P. putida MR3) and 63.14 \% (P. putida CSV86). The genome sequence of $P$. putida W619 was chosen as reference genome for the mapping, as this genome showed the highest overall nucleotide sequence identity (91.9\%) of all genomes of $P$. putida strains that had been available at the time of sequencing. For comparison, the genome of the most well-studied P. putida strain, strain KT2440,
Table 3 Nucleotide and gene count levels of the genome of P. putida SQ1

\begin{tabular}{lrc}
\hline Attribute & \multicolumn{2}{l}{ Genome (total) } \\
\cline { 2 - 3 } & \multicolumn{1}{c}{ Value } & \% of total ${ }^{2}$ \\
\hline Genome size (bp) & $5,328,888$ & 100.00 \\
DNA coding & $4,750,611$ & 89.15 \\
DNA G + C (bp) & $3,281,384$ & 61.58 \\
DNA scaffolds & 1,634 & 100.00 \\
Total genes & 5,925 & 100.00 \\
Protein coding genes & 5,824 & 98.30 \\
RNA genes & 101 & 1.70 \\
rRNA operon count & 9 & 0.15 \\
Genes with function prediction & 4,624 & 78.04 \\
Genes in paralog clusters & 4,497 & 75.90 \\
Genes assigned to COGs & 3,249 & 54.84 \\
Genes with Pfam domains & 4,781 & 80.69 \\
Genes with signal peptides & 535 & 9.03 \\
Genes with transmembrane helices & 1,270 & 21.43 \\
CRISPR count & 1 & \\
\end{tabular}

a) The total is based on either the size of the genome in base pairs or the tota number of protein coding genes predicted in the annotated draft genome

shows $49.3 \%$ overall nucleotide sequence identity to that of strain SQ1.

The genome of strain SQ1 $(5.3 \mathrm{Mb})$ is smaller compared to these of strains W619 (5.8 Mb) and KT2440 (6.2 Mb). The IMG abundance profiles for these three $P$. putida genomes indicated a lower abundance of transposases (COG3436 and COG3547) in strains SQ1 (2 total) and W619 (2 total) in comparison to KT2440 (21 total), as well as a lower abundance of ABC-type periplasmic, transmembrane or permease component genes (COG0834, COG0765, COG0715, COG0683, COG1132, COG0747 and COG4177) in strains SQ1 (46 total) and W619 (47 total) in comparison to KT2440 (68 total).

In the draft genome of $P$. putida SQ1, all genes for the Entner-Doudoroff pathway for glucose/glucose-6-phosphate are represented as part of the two gene clusters (operons) that are highly conserved within $P$. putida species (e.g., [30]), i.e., predicted genes for glucose-6-phosphate 1-dehydrogenase (IMG locus tag PpSQ1_03570), 6phosphogluconolactonase (PpSQ1_03569) and 2-keto3-deoxy-phosphogluconate aldolase (PpSQ1_03568) (gene cluster PP1022-24 in P. putida KT2440, respectively), and glucokinase (PpSQ1_04592), 6-phosphogluconate dehydratase (PpSQ1_02498/04591) and glyceraldehyde-3phosphate dehydrogenase (gene cluster PP1011-09 in $P$. putida KT2440, respectively); notably, the prediction of the dehydratase gene is distributed over two contigs of the draft assembly (and therefore has two IMG locus tags), however, the respective contigs are contiguous, as 
Table 4 Number of genes associated with general COG functional categories in P. putida SQ1

\begin{tabular}{lrrll}
\hline Code & Value & \% age & Description \\
\hline A & 167 & 4.60 & Translation, ribosomal structure and biogenesis \\
K & 1 & 0.03 & RNA processing and modification \\
K & 323 & 8.90 & Transcription \\
L & 107 & 2.95 & Replication, recombinant and repair \\
B & 1 & 0.03 & Chromatin structure and dynamics \\
D & 28 & 0.77 & Cell cycle control, Cell division, chromosome \\
& & & partitioning \\
V & 40 & 1.10 & Defense mechanisms \\
T & 204 & 5.62 & Signal transduction mechanisms \\
M & 179 & 4.93 & Cell wall/membrane/envelope biogenesis \\
N & 99 & 2.73 & Cell motility \\
U & 107 & 2.95 & Intracellular trafficking, secretion, and vesicular \\
& & & transport \\
O & 143 & 3.94 & Posttranslational modification, protein turnover, \\
& & & chaperones \\
C & 221 & 6.09 & Energy production and conversion \\
G & 183 & 5.04 & Carbohydrate transport and metabolism \\
E & 369 & 10.17 & Amino acid transport and metabolism \\
F & 87 & 2.40 & Nucleotide transport and metabolism \\
H & 158 & 4.35 & Coenzyme transport and metabolism \\
I & 147 & 4.05 & Lipid transport and metabolism \\
P & 216 & 5.95 & Inorganic ion transport and metabolism \\
Q & 91 & 2.51 & Secondary metabolites biosynthesis, transport \\
& & & and catabolism \\
R & 423 & 11.66 & General function prediction only \\
S & 335 & 9.23 & Function unknown \\
& 2,676 & 45.16 & Not in CoGs \\
& & & \\
& & &
\end{tabular}

a) The total is based on the total number of protein coding genes in the annotated genome

confirmed by PCR with a primer pair spanning over both contigs (this study). Further, all genes for a periplasmic entry into the Entner-Doudoroff pathway (e.g., [30]) were predicted in the draft genome of P. putida SQ1, i.e., for membrane-bound PQQ-dependent glucose dehydrogenases (e.g., PpSQ1_02906) and gluconate dehydrogenase complex (e.g., PpSQ1_00542), and for gluconokinase (PpSQ1_05341), 2-ketogluconate kinase (PpSQ1_05601/ 02858) and 2-ketogluconate 6-phosphate reductase (PpSQ1_02860).

No candidate genes for a sulfoglycolytic pathway for $\mathrm{SQ}$, as found in E. coli $\mathrm{K} 12$ [16], were detected in the draft genome sequence of strain SQ1, which supports the notion that a novel, alternative pathway for SQ is operative in strain SQ1 (see Introduction). Neither $P$. putida strains W619, KT2440 nor F1 grew with SQ when tested ([13] and this study). Further, our preliminary proteomic data (not shown) indicates that enzymes/ genes of the 'classical' Entner-Doudoroff pathway for glucose/glucose-6-phosphate (see above) are highly induced during growth with glucose, as expected, but not during growth with SQ. We concluded that additional genes in $P$. putida strain SQ1 are involved in the utilization of SQ, and that these genes might be located on contigs that resulted from the de novo assembly of the un-mapped reads. If appropriate, the proteomic identification of the core enzymes of this novel SQ degradation pathway based on the draft genome sequence established in this study, and their confirmation by biochemical and analytical-chemical methods, will be reported in a future communication.

\section{Conclusions}

Here, we present a summary classification and a set of features for Pseudomonas putida strain SQ1, together with the description of the shotgun genomic sequencing and annotation. The draft genome annotation contains no candidate genes for a sulfoglycolytic pathway for SQ, as found in $E$. coli $\mathrm{K} 12$, hence, the pathway operative in $P$. putida SQ1 represents a second, yet unknown bacterial degradation pathway for SQ. Furthermore, our preliminary proteomic data suggested that the 'classical' Entner-Doudoroff enzymes for a utilization of glucose/ glucose-6-phophate are not induced during growth with SQ and that, hence, additional enzymes in strain SQ1 are operative during utilization of SQ. Based on the draft genome sequence, these enzymes and genes can now be defined.

\section{Abbreviations \\ SQ: sulfoquinovose; SQDG: sulfoquinovosyl diacylglycerol; DHAP: dihydroxyacetone phosphate; LB: lysogeny broth; ABC: ATP-binding cassette.}

\section{Competing interests}

The authors declare that they have no competing interests.

\section{Authors' contributions}

A.-K.F. prepared the genomic DNA and did the PCR reactions and growth experiments. P.F. did the trimming, mapping, as well as the de novo assembly of the unmapped raw reads. A.-K.F. and D.S. wrote the manuscript.

\section{Acknowledgements}

We wish to thank Jaco Vangronsveld, Hasselt University, Belgium, for sending P. putida strain W619, Joachim Hentschel, University of Konstanz, for SEM operation, and DOE's JGI team for running IMG. A.-K.F wishes to thank Michael Weiss for proofreading and Ralf Schlesiger for help on the phylogenetic tree. The work of A.-K.F. was supported by the Konstanz Research School Chemical Biology (KoRS-CB), the work of P.F. by the University of Konstanz, and the work of D.S. by a DFG grant (SCHL 1936/1) and the University of Konstanz.

\section{Author details}

'Department of Biology, University of Konstanz, Konstanz, Germany. ${ }^{2}$ Konstanz Research School Chemical Biology, University of Konstanz, Konstanz, Germany. ${ }^{3}$ Genomics Center Konstanz, University of Konstanz, Konstanz, Germany.

Received: 2 February 2015 Accepted: 1 July 2015

Published online: 22 July 2015 


\section{References}

1. Migula W. Über ein neues System der Bakterien. Arb Bakteriol Inst Karlsruhe. 1894;1:235-8.

2. Trevisan V.I generi e le specie delle batteriacee. Zanaboni and Gabuzzi, Milan. 1889;1-35.

3. Nelson KE, Weinel C, Paulsen IT, Dodson RJ, Hilbert H. Martins dos Santos VA et al. Complete genome sequence and comparative analysis of the metabolically versatile Pseudomonas putida KT2440. Environmental Microbiol. 2002;4(12):799-808. doi:10.1046/j.1462-2920.2002.00366.x.

4. Nikel PI, Martínez-García E, Lorenzo V. Biotechnological domestication of Pseudomonas using synthetic biology. Nat Rev Microbiol. 2014;12(5):368-79. doi:10.1038/nrmicro3253.

5. Ohji S, Yamazoe A, Hosoyama A, Tsuchikane K, Ezaki T, Fujita N. The complete genome sequence of Pseudomonas putida NBRC $14164^{\top}$ confirms high intraspecies variation. Genome Announc. 2014;2(1). doi:10.1128/ genomeA.00029-14.

6. Molina L, Ramos C, Duque E, Ronchel MC, García JM, Wyke L, et al. Survival of Pseudomonas putida KT2440 in soil and in the rhizosphere of plants under greenhouse and environmental conditions. Soil Biol Biochem. 2000;32(3):315-21. doi:10.1016/S0038-0717(99)00156-X.

7. Dos Santos VA, Heim S, Moore ER, Stratz M, Timmis KN. Insights into the genomic basis of niche specificity of Pseudomonas putida KT2440. Environ Microbiol. 2004;6(12):1264-86. doi:10.1111/j.1462-2920.2004.00734.x.

8. Chen C, Bauske EM, Musson G, Rodriguez-Kabana R, Kloepper JW. Biological control of Fusarium wilt on cotton by use of endophytic bacteria. Biol Control. 1995;5:83-91. doi:10.1128/JB.182.9.2363-2369.2000.

9. Jiménez Jl, Miñambres B, García JL, Díaz E. Genomic analysis of the aromatic catabolic pathways from Pseudomonas putida KT2440. Environ Microbiol. 2002:4(12):824-41. doi:10.1046/j.1462-2920.2002.00370.x.

10. Timmis KN. Pseudomonas putida: a cosmopolitan opportunist par excellence. Environ Microbiol. 2002;4(12):779-81.

11. Gomes NC, Kosheleva IA, Abraham WR, Smalla K. Effects of the inoculant strain Pseudomonas putida KT2442 (pNF142) and of naphthalene contamination on the soil bacterial community. FEMS Microbiol Ecol. 2005;54(1):21-33. doi:10.1016/j.femsec.2005.02.005.

12. Ward PG, Goff M, Donner M, Kaminsky W, O'Connor KE. A two step chemo-biotechnological conversion of polystyrene to a biodegradable thermoplastic. Environ Sci Technol. 2006;40(7):2433-7.

13. Denger K, Huhn T, Hollemeyer K, Schleheck D, Cook AM. Sulfoquinovose degraded by pure cultures of bacteria with release of $C_{3}$-organosulfonates: complete degradation in two-member communities. FEMS Microbiol Lett. 2012;328(1):39-45. doi:10.1111/j.1574-6968.2011.02477.x.

14. Benning C. Biosynthesis and function of the sulfolipid sulfoquinovosyl diacylglycerol. Annu Rev Plant Biol. 1998;49:53-75.

15. Harwood JL, Nicholls RG. The plant sulpholipid- a major component of the sulphur cycle. Biochem Soc Trans. 1979;7(2):440-7.

16. Denger K, Weiss M, Felux AK, Schneider A, Mayer C, Spiteller D, et al. Sulphoglycolysis in Escherichia coli K-12 closes a gap in the biogeochemical sulphur cycle. Nature. 2014;507(7490):114-7. doi:10.1038/nature12947.

17. Field D, Garrity G, Gray T, Morrison N, Selengut J, Sterk P, et al. The minimum information about a genome sequence (MIGS) specification. Nat Biotechnol. 2008;26(5):541-7. doi:10.1038/nbt1360.

18. Langmead B, Salzberg SL. Fast gapped-read alignment with Bowtie 2. Nat Methods. 2012;9(4):357-9. doi:10.1038/nmeth.1923.

19. Zerbino DR, Birney E. Velvet: algorithms for de novo short read assembly using de Bruijn graphs. Genome Res. 2008;18(5):821-9. doi:10.1101/ gr.074492.107.

20. Mavromatis K, Ivanova NN, Chen IM, Szeto E, Markowitz VM, Kyrpides NC The DOE-JGl standard operating procedure for the annotations of microbial genomes. Stand Genomic Sci. 2009;1(1):63-7. doi:10.4056/sigs.632.

21. Hyatt D, Chen GL, Locascio PF, Land ML, Larimer FW, Hauser L. Prodigal: prokaryotic gene recognition and translation initiation site identification. BMC Bioinformatics. 2010;11:119. doi:10.1186/1471-2105-11-119.

22. Magrane M, Consortium U. UniProt Knowledgebase: a hub of integrated protein data. The Journal of Biological Databases and Curation. 2011:43:bar009. doi:10.1093/database/bar009.

23. Haft DH, Selengut JD, White $O$. The TIGRFAMs database of protein families. Nucleic Acids Res. 2003;31(1):371-3. doi:10.1093/nar/gkg128.

24. Finn RD, Bateman A, Clements J, Coggill P, Eberhardt RY, Eddy SR, et al. Pfam: the protein families database. Nucleic Acids Res. 2014;42(Database issue):D222-30. doi:10.1093/nar/gkt1223.
25. Kanehisa M, Goto S, Sato Y, Furumichi M, Tanabe M. KEGG for integration and interpretation of large-scale molecular data sets. Nucleic Acids Res. 2012:40(Database issue):D109-14. doi:10.1093/nar/gkr988.

26. Tatusov RL, Galperin MY, Natale DA, Koonin EV. The COG database: a tool for genome-scale analysis of protein functions and evolution. Nucleic Acids Resesarch. 2000;28(1):33-6.

27. Hunter S, Apweiler R, Attwood TK, Bairoch A, Bateman A, Binns D, et al. InterPro: the integrative protein signature database. Nucleic Acids Res. 2009;37(Database issue):D211-5. doi:10.1093/nar/gkn785.

28. Lowe TM, Eddy SR. tRNAscan-SE: a program for improved detection of transfer RNA genes in genomic sequence. Nucleic Acids Res. 1997;25(5):955-64. doi:10.1093/nar/25.5.0955

29. Pruesse E, Quast C, Knittel K, Fuchs BM, Ludwig W, Peplies J, et al. SILVA: a comprehensive online resource for quality checked and aligned ribosomal RNA sequence data compatible with ARB. Nucleic Acids Res. 2007;35(21):7188-96. doi:10.1093/nar/gkm864.

30. Daddaoua A, Krell T, Ramos JL. Regulation of glucose metabolism in Pseudomonas: the phosphorylative branch and entner-doudoroff enzymes are regulated by a repressor containing a sugar isomerase domain. J Biol Chem. 2009;284(32):21360-8. doi:10.1074/jbc.M109.014555.

31. Tamura K, Stecher G, Peterson D, Filipski A, Kumar S. MEGA6: Molecular Evolutionary Genetics Analysis version 6.0. Mol Biol Evol. 2013;30(12):2725-9. doi:10.1093/molbev/mst197.

32. Ashburner M, Ball CA, Blake JA, Botstein D, Butler H, Cherry JM, et al. Gene ontology: tool for the unification of biology. The Gene Ontology Consortium. Nat Genet. 2000;25(1):25-9. doi:10.1038/75556.

33. Woese CR, Kandler O, Wheelis ML. Towards a natural system of organisms: proposal for the domains Archaea, Bacteria, and Eucarya. Proc Natl Acad Sci USA. 1990;87(12):4576-9. doi:10.1073/pnas.87.12.4576.

34. Garrity GM, Bell JA, Lilburn T. Phylum XIV. Proteobacteria phyl. nov. In: Garrity GM, Brenner DJ, Krieg NR, Staley JT, editors. Bergey's Manual of Systematic Bacteriology, Second Edition, Volume 2, Part B. New York: Springer; 2005. p. 1.

35. Validation of publication of new names and new combinations previously effectively published outside the IJSEM. List no. 106. Int J Syst Evol Micobiol. 2005;55:2235-8.

36. Skerman VBD, McGowan V, Sneath PHA. Approved Lists of Bacterial Names. Int J Syst Bacteriol. 1980;30:225-420. doi:10.1099/00207713-30-1-225.

37. Orla-Jensen $\mathrm{S}$. The main lines of the natural nacterial system. J Bacteriol. 1921;6(3):263-73.

38. Garrity GM, Bell JA, Lilburn T. Order IX. Pseudomonadales. In: Garrity GM, Brenner DJ, Krieg NR, Staley JT, editors. Bergey's Manual of Systematic Bacteriology, Second Edition, Volume 2, Part B. New York: Springer; 2005. p. 323

39. Winslow CE, Broadhurst J, Buchanan RE, Krumwiede C, Rogers LA, Smith GH. The families and genera of the bacteria: preliminary report of the committee of the society of american bacteriologists on characterization and classification of bacterial types. J Bacteriol. 1917;2(5):505-66.

40. Judicial Commission. Opinion 5: conservation of the generic name Pseudomonas Migula 1894 and designation of Pseudomonas aeruginosa (Schroeter) Migula 1900 as type species. Int Bull Bacteriol Nomencl Taxon. 1952;2:121-2.

\section{Submit your next manuscript to BioMed Central and take full advantage of:}

- Convenient online submission

- Thorough peer review

- No space constraints or color figure charges

- Immediate publication on acceptance

- Inclusion in PubMed, CAS, Scopus and Google Scholar

- Research which is freely available for redistribution 